\title{
Educomunicação: Histórias em quadrinhos e fanzines no ensino de Artes
}

\author{
Roberto Elisio dos Santos \\ Jornalista, livre-docente em Comunicação pela ECA-USP, professor da Escola de Comunicação, \\ do curso de Pedagogia e do Programa de Pós-graduação em Comunicaşão da Universidade \\ Municipal de São Caetano do Sul (USCS) e vice-coordenador do Observatório de Histórias \\ em Quadrinhos da ECA-USP. \\ E-mail: roberto.elisio@uscs.edu.br
}

José Luis dos Santos

Mestre em Comunicação pelo Programa de Pós-graduação em Comunicação da Universidade Municipal de São Caetano do Sul (USCS) e professor de Artes do ensino médio estadual.

E-mail: jluizsan@gmail.com

Resumo: Este artigo resulta de pesquisa de mestrado aprovada na Universidade Municipal de São Caetano do Sul (USCS), cujo objetivo foi investigar a utilização das histórias em quadrinhos ( $\mathrm{HQs}$ ) e de fanzines como forma de inovação para a docência da disciplina de Artes no ensino médio. De caráter qualitativo e de nível exploratório, o estudo se desenvolveu na interface dos campos da educação com a comunicação. Este trabalho, portanto, busca identificar referências estéticas comuns a determinadas produções de HQs com relação a períodos específicos das vanguardas modernas da arte. Dentre as conclusões, salientou-se o fato de que é necessário que os espaços escolares ofereçam uma experiência cognitiva que valorize mais as relações sociais, respeitando o direito do jovem à comunicação e à informação. Para que isso fosse possível, propõe-se a realização de oficina de fanzines de quadrinhos.

Palavras-chave: histórias em quadrinhos; artes; educomunicação; ensino; fanzine.
Abstract: This article is the result of a master's research approved at the Municipal University of São Caetano do Sul (USCS). The objective was investigate the use of Comics and fanzines as an innovation for teaching visual arts in high school. This study, being one of qualitative nature and exploratory level, was developed in the interface between education and communication fields. The article, therefore, seeks to identify common aesthetic references in certain Comics productions regarding specific periods of modern avant-garde art. Among the conclusions, it was highlighted the fact that it is necessary that school spaces provide a learning experience that puts more emphasis to social relations, respecting young people's right to communication and information. To make this possible, it is proposed the realization of a comics fanzine workshop.

Keywords: comics; arts; educommunication; teaching; fanzine. 
1. CITELLI, Adilson Odair. Comunicação, educação e linguagem. In: SOARES, Ismar de Oliveira. Cadernos de educomunicação. Caminhos da educomunicação (coord.). 2. ed. São Paulo: Editora Salesiana, 2003 , p. 65

2. CASTELLS, Manuel. A sociedade em rede. 1. v. São Paulo: Paz e Terra, 1999

3. CITELLI, Adilson Odair. Comunicação e Educação: a linguagem em movimento. São Paulo: Senac, 2004, p. 84.

4. SOARES, Ismar de Oliveira. Educomunicação: o conceito, o profissional, a aplicação: contribuições para a reforma do ensino médio. São Paulo: Paulinas, 2011, p. 16.

5. FREIRE, Paulo. Educação como prática da liberdade. 23. ed. Rio de Janeiro: Paz e Terra, 2002.

6. CAVALCANTE, Luis Adolfo de Oliveira; CEDRO, Wellington Lima. Uma análise lógico-histórica da relação entre as histórias em quadrinhos e a educação. In: PEREIRA, Ana Carolina Costa; ALCÂNTARA, Cláudia Sales de. História em quadrinhos: interdisciplinaridade e educação. São Paulo: Reflexão, 2016, pp. 57-82.

\section{INTRODUÇÃO}

A sociedade contemporânea encontra-se em um momento de intensas transformações tecnológicas, em diversas áreas do conhecimento, e em especial das tecnologias da comunicação e da informação, com o aparecimento de novas formas de relacionamentos, novos modos de agir e de pensar, novas relações de trabalho, de lazer, de comunicação e de informação. Para Citelli ${ }^{1}$, o "[...] conhecimento se aliou, definitivamente, à criatividade capaz de otimizar inovações e ideias que irão alterar os ritmos produtivos e construir os novos impérios gerenciadores da vida no planeta”.

Nesse âmbito, duas áreas que historicamente colocaram-se de forma antagônica vêm estreitando as suas relações, tendo como pano de fundo o atual momento por que passa a sociedade contemporânea: a comunicação e a educação. Essa aproximação evidencia a urgente necessidade de novos métodos de ensino e de aprendizagem, que possam resgatar os jovens e incluí-los nos ambientes escolares formais ou não, pois, em tempos de sociedade da informação ${ }^{2}$, os jovens precisam de ambientes motivadores, nos quais o aprendizado possa acontecer de forma mais inspiradora, prazerosa e menos impositiva, como evidencia Citelli3:

Os modelos escolares com os quais convivemos - frequentemente chamados, à falta de melhor termo, de tradicionais - estão construídos em torno de três eixos básicos: hierarquia, coerção, exclusão. A tendência, nesse tipo de escola, foi a de elaborar programas educativos fechados em que não se ajustam comportamentos que possam levar à quebra das sequências hierárquicas justificadas pela lógica da melhor escolha dos conteúdos e pela autoridade de quem os selecionou.

Não obstante as ações do governo federal, como a LDB (Leis de Diretrizes e Bases da Educação, de 1996), que segundo Soares ${ }^{4}$, “[...] previam que esta modalidade de ensino abandonasse a perspectiva conteudista e fragmentada que a caracteriza para adotar uma visão interdisciplinar de ensino [...]”, o que se encontra ainda é uma grande resistência por parte da escola, que não tem muito claro qual direção seguir. Engessada por um pensamento retrógrado, que exclui aqueles a quem deveria incluir, a escola formal resiste ainda em adotar em suas estruturas as inovações da sociedade do conhecimento, optando em se utilizar de métodos tradicionais de autoridade, em vez de uma relação dialógica e democrática, conforme Freire ${ }^{5}$.

Por esse motivo, propõe-se, neste texto, a utilização de histórias em quadrinhos no processo educativo, especificamente nas aulas de Artes ministradas para o ensino médio, como forma de estabelecer um diálogo maior entre o estudante e o educador, utilizando um meio que estabelece uma relação entre imagem e texto, o que pode aguçar a imaginação e a percepção dos discentes, seguindo as ideias Cavalcante e Cedro ${ }^{6}$. Para esses autores, "em âmbito educacional as HQs podem ser utilizadas como ferramenta para a disseminação de ideais [grifo do original] na campanha de ressignificação social". E acrescentam: "Trabalhando nesse sentido, os professores podem levar os alunos a uma reflexão”. Ao refletir 
a partir das HQs, os educandos podem compreender melhor não apenas os conteúdos transmitidos, mas também a vida e a sociedade em que se inserem.

\section{EDUCOMUNICAÇÃO: A EXPRESSÃO COMUNICATIVA ATRAVÉS DAS ARTES}

Nesse contexto, a Educomunicação se apresenta como um novo espaço interdiscursivo, um novo campo de intervenção social, atuando nos territórios da educação e da comunicação, levando em conta as relações entre o sujeito social e as mídias. Para Schaun ${ }^{7}$, "[...] a inter-relação comunicação/educação ganhou densidade própria e se afirma como um campo de intervenção social específico", ao proporcionar aos jovens a construção de quadros de significação com relação aos aspectos do mundo que os rodeiam.

Soares acrescenta ainda que a Educomunicação propõe-se a "ampliar as condições de expressão da juventude como forma de engajá-la em seu próprio processo educativo $[. . .]^{8}$, evidenciando a constituição de novos espaços educativos — ou ecossistemas comunicativos - para o compartilhamento democrático dos saberes, numa relação democrática e dialógica, configurando-se, assim, como um espaço de grande potencial emancipador e inovador para o desenvolvimento de novos métodos de ensino e de aprendizagem, bem como para o ensino da disciplina de artes".

\section{CORRESPONDÊNCIA ESTÉTICA ENTRE HQS E AS VANGUARDAS MODERNAS DA ARTE}

As proximidades históricas e estéticas entre o desenvolvimento das artes visuais e a produção das HQs tornam possível uma relação de correspondência dos movimentos das vanguardas modernas da arte com as características estéticas das histórias em quadrinhos, capaz de propiciar ações, interpretações ou métodos que possam lançar luzes às novas abordagens de ensino e aprendizagem, em especial para o ensino da disciplina de Artes no ensino médio. Assim, para Rahde ${ }^{9}$ :

Na maioria das vezes ignorada pela História da Arte, a história em quadrinhos, que nasceu como imagem narrativa desde o início das primeiras manifestações da pintura, apresentou-se com formas artísticas, buscou reforço nas correntes da arte, ganhando espaço como arte visual de comunicação pelas mãos e mentes talentosas de diversos artistas plásticos: o já citado Burne Hogarth, de tendência barroca; Alex Raymond, que experimentou diversos estilos, firmando-se no traço clássico; Hal Foster, pintor paisagista; Chester Gould, de tendência expressionista; Philippe Druillet, que uniu o barroco e o surrealismo ao realismo fantástico na sua visão pós-moderna.
7. SCHAUN, Angela. Educomunicação: reflexões e princípios. Rio de Janeiro: Mauad, 2002, p. 79.

8. SOARES, Ismar de Oliveira, op. cit., p. 15.

9. RAHDE, Maria Beatriz Furtado. Estética moderna \& pós-moderna. Porto Alegre: EDIPUCRS, 2000, p. 47. 


\subsection{Relações estéticas das HQs com o dadaísmo}

Na história Malpractice Suite, realizada pelo quadrinista estadunidense Art Spiegelman, por exemplo, os quadrinhos são sobrepostos como se tivessem sido recortados e colados, técnica bastante utilizada nas obras dadaístas, como nas produções de Hannah Höch.

Figura 1. Dadaísmo

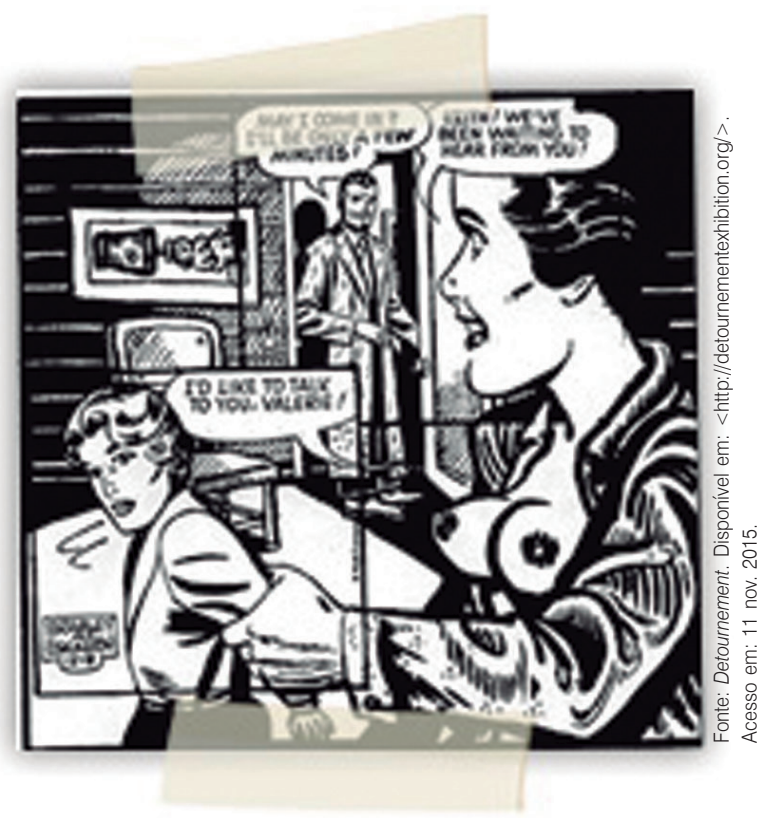

Recorte da HQ Malpractice Suite, de Art Spiegelman

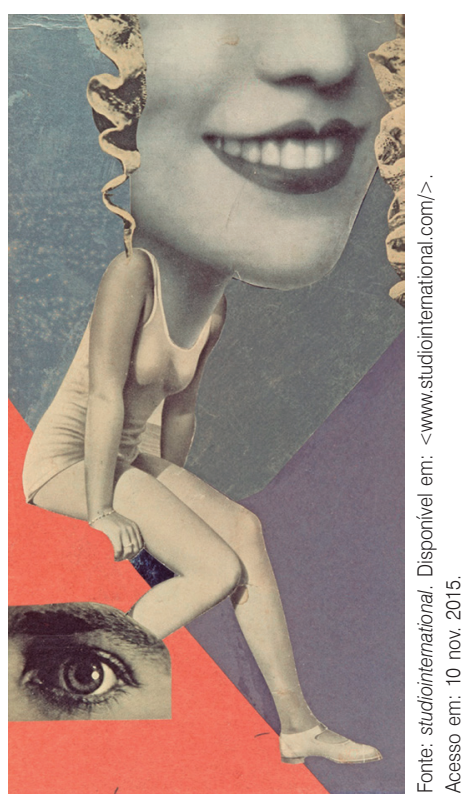

Fotomontagem de Hannah Höch, Made for a Party, de 1936

Segundo Proença ${ }^{10}$ :

[...] os dadaístas propunham que a criação artística se libertasse das amarras do pensamento racionalista e sugeriam que ela fosse apenas o resultado do automatismo psíquico, selecionando e combinando elementos ao acaso. Na pintura, essa atitude foi traduzida por obras que usaram o recurso da colagem.

Spiegelman, em Malpractice Suite, faz uma severa crítica ao estilo de vida

10. PROENÇA, Graça. História da Arte. São Paulo: Ática, 2003, p. 167.

11. MAZUR, Dan; DANNER, Alexander. Quadrinhos: história moderna de uma arte global. São Paulo: WMF Martins Fontes, 2014, p. 41. sociedades contemporâneas, em que as pessoas são bombardeadas por toda sorte de informação/imagens que chegam a todo o momento, o que é característico também do movimento dadaísta, com fortes críticas aos valores da sociedade da época. De acordo com Mazur e Danner ${ }^{11}$ :

Malpractice Suite, um tour de force de duas páginas [publicada na revista] Arcade n. 6 [1976], combina colagem e cartum, numa considerável violência para com a tira diária de Rex Morgan, M. D. (de Marvin Bradley, Frank Edgington e Dal Curtis [Dr. Nicholas P. Dallis]). Os quadrinhos da tira são recortados e duplicados 
em ordem diferente dentro de quadrinhos maiores, enquanto as figuras dos personagens ultrapassam as bordas do quadrinho em um estilo grosseiro, em contraste chocante com a tira original. [...] Não é uma paródia, mas um comentário visceral sobre o bombardeio constante de imagens fragmentadas na vida moderna encharcada de mídia.

\subsection{Relações estéticas das HQs com o expressionismo}

\section{Figura 2. Expressionismo}

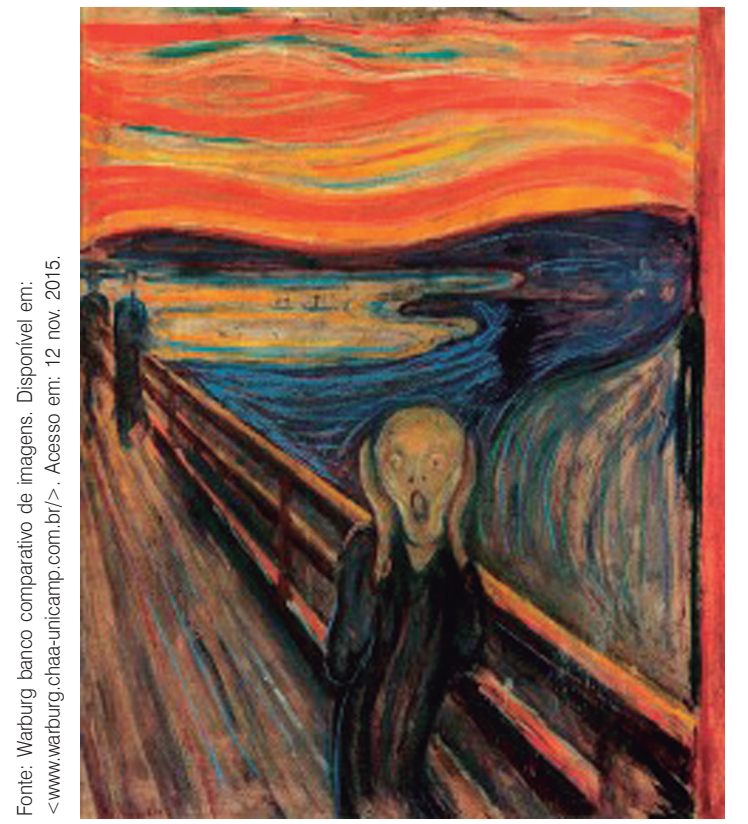

O Grito, de Edvard Munch.

Óleo, têmpera e pastel

sobre cartão adaptada (1893)

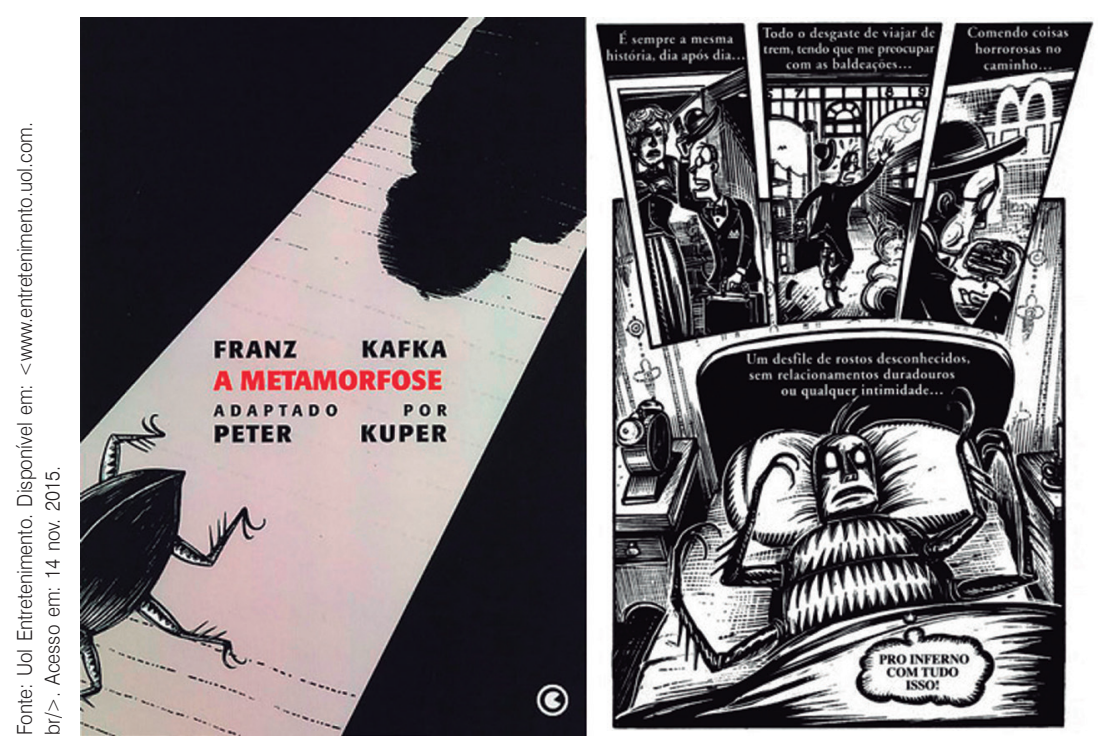

Recorte da obra A Metamorfose, de Kafka, por Peter Kuper 
Em $O$ Grito, Edvard Munch, por meio de traços carregados e cores densas, expressa a dor e o desespero de uma figura caricata e anônima, pairando sobre uma ponte. A utilização de cores quentes e frias, tinta pastosa e pinceladas fortes ao fundo - características estéticas próprias do movimento expressionista — dá o tom de solidão e tristeza à obra.

Para Batistone Filho ${ }^{12}$, Munch, "na gravura O Grito, sua maior obra, centraliza o rosto de um homem como fonte de sons e ondas de cor, que se dilatam concentricamente no ar, espalhando o sentimento trágico da vida e a sensação de catástrofe iminente". O expressionismo caracteriza-se, sobretudo, por exteriorizar o estado de espírito do ser humano, suas mazelas, suas dores e frustrações, contrapondo-se, nesse sentido, radicalmente ao impressionismo, considerado como uma arte figurativa.

Peter Kuper, em sua HQ A Metamorfose, baseada na obra literária de Franz Kafka, faz também várias referências ao expressionismo, como a predominância do contraste entre luz e sombra, e o ambiente predominantemente sombrio. A adaptação para os quadrinhos preserva, pelos traços do quadrinista, o mesmo clima vivido pela personagem no original de Kafka, com a presença constante do preto e das sombras, e os vários tons de cinza, além do traço marcante, que reflete o estado de espírito do artista. Para Santos $^{13}$, Kuper ressalta "o clima de absurdo retratado pelo autor tcheco".

\subsection{Relações estéticas das HQs com o art nouveau}

12. BATISTONE FILHO, Duílio. Pequena história da arte. 7. ed. Campinas: Papirus, 1996, p. 114

13. SANTOS, Roberto Elísio dos. VERGUEIRO, Waldomiro. Histórias em quadrinhos no processo de aprendizado: da teoria à prática. In: EccoS - Revista Científica, n. 27, São Paulo, Uninove jan./abr. 2012, pp. 81-95. Disponivel em: <http:// repositorio.uscs.edu.br/ handle/123456789/244> Acesso em: 14 out. 2015.

\section{Figura 3. Art nouveau}

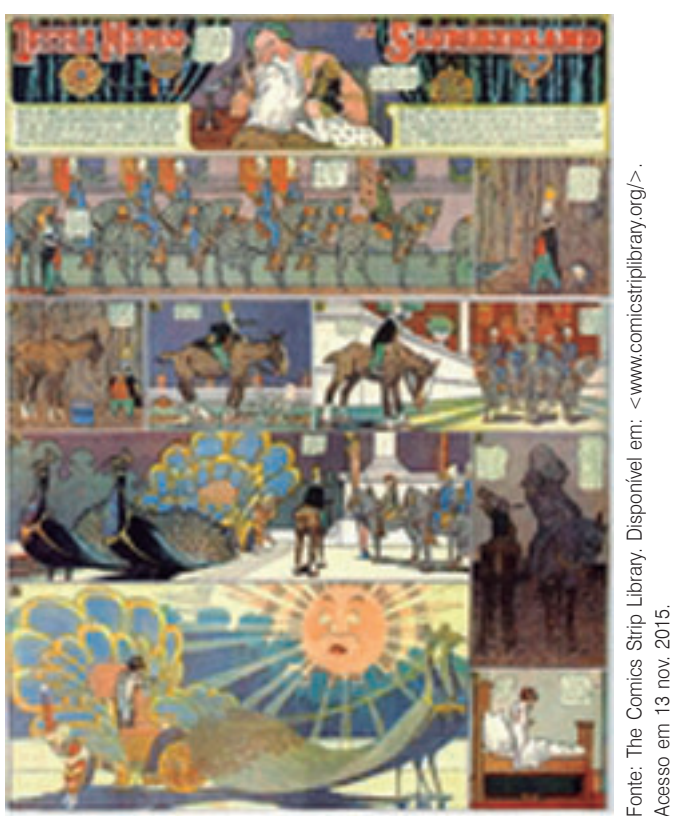

Little Nemo, de Winsor McCay

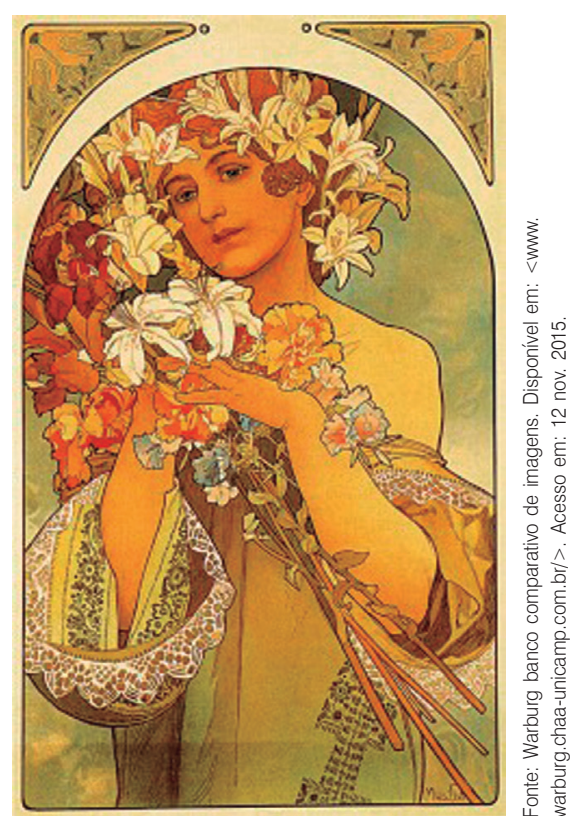

Litogravura de Alphonse Mucha 
Little Nemo foi uma das primeiras obras de quadrinhos a absorver as tendências e estilos da arte, inovando suas estruturas visuais e textuais, a partir dos elementos estéticos do art nouveau. Produzidas por Winsor McCay a partir de 1905, as histórias de Little Nemo tratam dos sonhos de um garoto, que é sempre acordado no último quadrinho. Como afirma Franco: ${ }^{14}$

[...] com certeza um dos primeiros trabalhos a explorar de forma dinâmica e ousada as possibilidades ilimitadas da linguagem dos quadrinhos foi Little Nemo in Slumberland, HQ seriada criada em 1905 pelo ilustrador norte-americano Winsor McCay, considerada um dos grandes clássicos das HQs. McCay é um dos primeiros inovadores dos chamados comics, ele incorpora influências de Art Nouveau, Art Déco, entre outras, e revoluciona os enquadramentos, explorando os grandes planos, antecipando as possibilidades da lente grande angular usada posteriormente no cinema. McCay produziu uma obra sem precedentes, que até hoje emociona pela exuberância, requinte e vanguarda.

Na litografia de Alphonse Mucha, percebe-se também a forte presença das características do art nouveau, uma arte que prima pelo uso das cores frias, temática naturalista, curvas, movimentos musicais, referências à arte japonesa, além da aura de leveza e otimismo das obras.

\section{APLICAÇÃO PRÁTICA: OFICINA DE FANZINE DE QUADRINHOS}

"Educomunicação é essencialmente práxis social, originando um paradigma orientador da gestão em sociedade" ${ }^{15}$. A vocação natural desse novo campo de estudos é interferir junto a espaços escolares, formais ou não, no sentido de potencializar ações de intervenção social, visando à construção de ambientes inovadores e democráticos, capazes de proporcionar experiências cognitivas novas.

Nesse sentido, para dinamizar as aulas de Artes no ensino médio, propõe-se a realização de oficina de fanzines de quadrinhos. Os fanzines são produções artesanais utilizadas para veicular informações sobre determinados assuntos de gosto pessoal do autor, como histórias em quadrinhos, literatura etc. Segundo Magalhães ${ }^{16}$ :

Os fanzines surgiram nos Estados Unidos da América no final da década de 1920, a partir da iniciativa dos fãs de ficção científica. Logo eles se tornaram o veículo dos novos autores não só de ficção científica, mas também de qualquer expressão artística ou literária.

Caracterizados principalmente por seu caráter autoral, o que dá a sua produção um toque extremamente pessoal, os fanzines valorizam a criação, resgatando a autoestima e o sentimento de pertencimento. Na visão de Rossetti e Santoro Júnior ${ }^{17}$ :

Os assuntos tratados nos fanzines são objetos de paixão de pessoas que se unem por este motivo, o editor é o indivíduo que não se contenta em assumir uma posição
14. FRANCO, Edgar. História em Quadrinhos e Arquitetura. 2. ed. João Pessoa: Marca de Fantasia, 2012, pp. 8-9. Disponível em: <http:// marcadefantasia.com/ livros/quiosque/hqearquitetura/HO\%20 $\% 20$ Arquitetura-Edgar\%20 Franco.pdf $>$. Acesso em: 22 out. 2015.

15. SOARES, Ismar de Oliveira. Educomunicação: o conceito, o profissional, a aplicação: contribuições para a reforma do ensino médio. São Paulo: Paulinas, 2011, p. 13.

17. ROSSETTI, Regina; Santoro JUNIOR, David. Fanzine Punk como mídia alternativa. Revista ALTERJOR. 2, v. 2, ed. 4, jul./ dez. 2011, p. 67. Disponível em <file:///C:/Users/User/ Downloads/153-572-1-PB. pdf >. Acesso em: $10 \mathrm{dez}$. 2015.16. MAGALHÃES, Henrique. O rebuliço apaixonante dos fanzines. 4. ed. João Pessoa: Marca de Fantasia, 2014, p. 4. 
18. PINTO, Renato Donizete. Fanzine na Educação: algumas experiências em sala de aula. João Pessoa: Marca de Fantasia, 2013.

19. ANDRAUS, Gazy; SANTOS NETO, Elydio dos. Dos Zines aos Biografic zines: Narrativas Visuais no Processo de Formação Continuada de Docentes-Pesquisadores. Imaginário: Humor, Quadrinhos, Games e Fanzines, n. 1. Paraíba, Marca de Fantasia, 2011, pp. 48. Disponível em: <http://marcadefantasia. com/revistas/imaginario/ imaginario-01-10/imaginario-01/imaginario-1. pdf\#page $=47>$. Acesso em: 20 dez. 2015. passiva em relação a sua adoração, ele deseja investigar, conhecer os detalhes do objeto. A publicação é o meio pelo qual ele reúne seus semelhantes para iniciar uma discussão e assim debater os assuntos de interesse pessoais e do grupo.

Os fanzines configuram-se desse modo como importante elemento de protagonismo pessoal. Para Pinto $(2013)^{18}$, "o mais importante neste processo é a personalidade dada à publicação, única e autoral”.

Figura 4. Capa do fanzine Top! Top!, editado por Henrique Magalhães

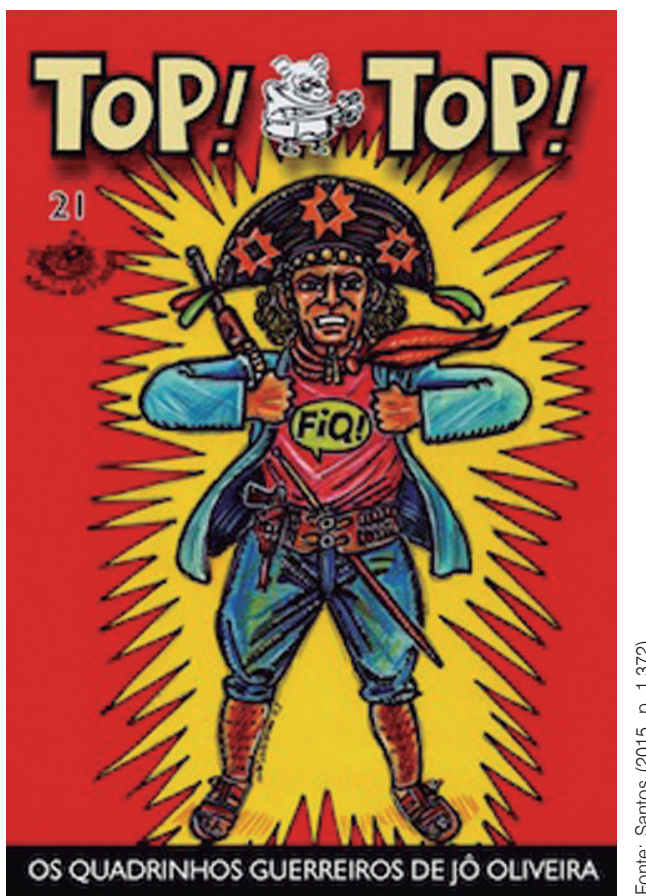

Algumas experiências - como a produção dos biografic zines como instrumento didático pedagógico, desenvolvida no curso de mestrado em Educação da Universidade Metodista de São Paulo no processo formativo de docentes pesquisadores - têm demonstrado as grandes possibilidades da utilização de novos métodos de ensino e aprendizagem. Os alunos, a partir da produção de fanzine de quadrinhos, puderam contar a sua narrativa de vida, como forma de autoconhecimento e autoralidade. Andraus e Santos Neto ${ }^{19}$ definem biografic zine como:

[...] um fanzine (do inglês fanatic + magazine $=$ revista do fã $)$ que tem por objeto as histórias de vida: contar experiências de vida e formação tendo como objetivos principais o autoconhecimento, a partilha de narrativas pessoais com outros, o trabalho com as imagens e o desenvolvimento de autoralidade. 
Segundo Fernandes et $\mathrm{al}^{20}$ :

Hoje entende-se que a associação de imagens e textos, além dos códigos específicos das HQ como rabiscos de expressão e movimento, colabora para um entendimento mais eficiente da mensagem e torna mais fácil a compreensão de temas complexos, justamente por comportar dois canais comunicativos de forma integrada.

Salienta-se que as HQs ocupam papel de destaque no processo de adequação de uma linguagem técnica/formal para uma linguagem imagética ao transcodificar uma linguagem formal/técnica/textual para uma linguagem visual, proporcionando uma experiência mais ampla, seja tanto de leitura quanto de compreensão. Dessa forma, propõe-se uma oficina de fanzine de quadrinhos como ação educomunicativa junto a espaços escolares, numa linha definida como quadrinhos "poético-filosóficos" também chamados de "quadrinhos filosóficos", sendo um dos seus principais representantes o professor Gazy Andraus. Para esse educador ${ }^{21}$, quadrinhos filosóficos:

São em geral histórias não muito compridas, com teor universal de significados, de reflexão com relação ao que é o ser humano e o que ele quer em sua existência, muitas vezes travestido como seres utópicos, extraterrestres. Os quadrinhos do Edgar Franco, por exemplo, são diferentes, pois possuem mais castelos e dragões e peixes e símbolos nas histórias. O roteiro geralmente descreve um aforismo uma frase ou algumas frases de reflexão, contundentes, filosóficas, por que o ser humano é feliz, é triste? O que ele quer nessa existência? A relação do ser humano com outro ser humano, entre outros.

Figura 5. Quadrinhos poético-filosóficos de Gazy Andraus

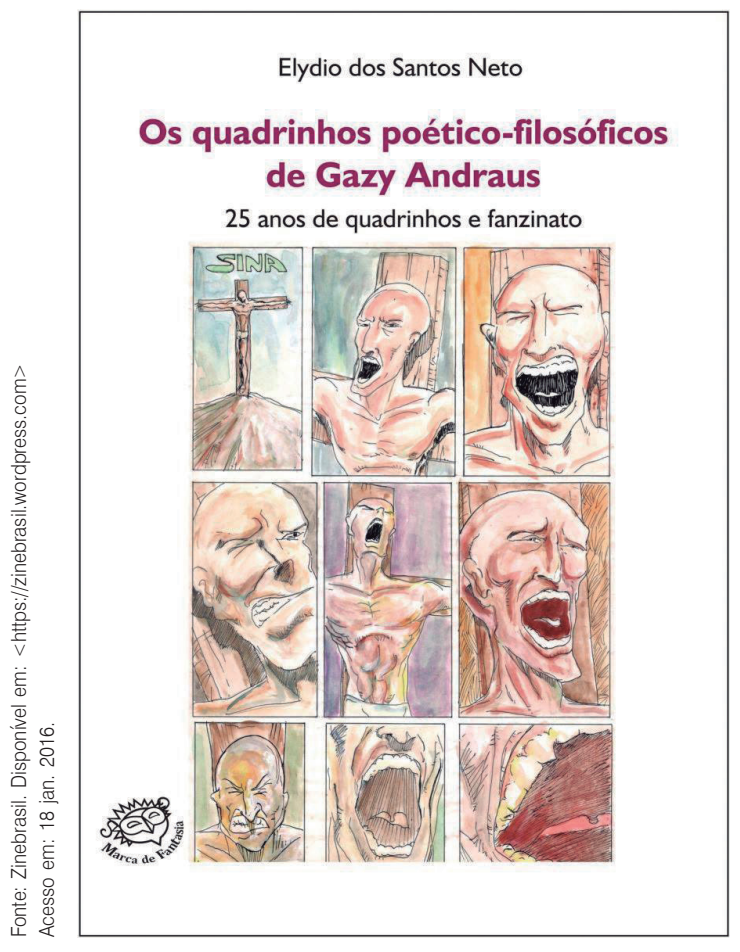

20. FERNANDES, Hylio Laganá et al. GIBIOzine - Revista de divulgação científica e cultural. In: Nona Arte - Revista Brasileira de Pesquisas em Histórias em Quadrinhos, v. 1 , n. 2, 2013, p. 36. Disponível em: <www2. eca.usp.br/nonaarte/ojs/ index.php/nonaarte/article/view/18>. Acesso em: 18 dez. 2015.

21. Entrevista concedida ao autor deste trabalho em 13 de fevereiro de 2015. 
A oficina ocorreria no contraturno das aulas, sendo composta por cinco encontros, como descritos abaixo:

- História das HQs, e HQs como linguagem: características principais e utilização na educação.

- Quadrinhos poético-filosóficos: o que são? Características principais, apresentação de trabalhos do professor Gazy Andraus, entre outros.

- Fanzines: o que são? Histórico e características. Sua importância como meio de comunicação.

- Construção de um fanzine de quadrinhos poético-filosóficos com o tema: História da Arte - Modernismo. Os alunos poderão escolher um movimento artístico do período da história da arte denominado de modernismo, como o surrealismo, por exemplo, e, partindo de suas características estéticas, produzir quadrinhos poético-filosóficos. Poderão ser utilizados os mais diversos materiais e técnicas, como colagens, desenhos, entre outros. Não é preciso saber desenhar.

- Encontro para apresentação, exposição e trocas de trabalhos.

\section{CONSIDERAÇÕES FINAIS}

Este artigo abordou os principais pensamentos que nortearam a pesquisa de mestrado que se desenvolveu sob o título Histórias em Quadrinhos e Arte Educação: sistemas abertos e dialógicos como inovação para o aprendizado de artes no Ensino Médio, e procurou expandir os debates sobre possíveis caminhos ampliadores da prática docente para além dos métodos tradicionais de ensino. Nesse sentido, foram salientados aspectos como o exercício da prática educativa, sob o âmbito da educomunicação, um novo campo de estudo na interface da educação e da comunicação, que, por meio de projetos de intervenção social, procura despertar no jovem a consciência da sua importância como sujeito social transformador, respeitando o seu direito à comunicação e à informação, ao estimulá-lo para o seu natural protagonismo e a sua necessária participação nos rumos do país.

Assim, além da utilização de histórias em quadrinhos pelo professor de Artes como uma ferramenta para a compreensão dos estilos característicos das principais vanguardas do século XX, também é apresentada a proposta de realização de oficina de fanzine de quadrinhos poético-filosóficos como

22. ANDRAUS, Gazy. O trabalho com histórias em quadrinhos $(\mathrm{HO})$ no ensino universitário. In: SANTOS NETO, Elydio; SILVA, Marta Regina Paulo da (orgs.). Histórias em quadrinhos \& Educação: formação e prática docente. São Bernardo do Campo: Universidade Metodista de São Paulo, 2011, pp. 33-55. alternativa aos métodos tradicionais de ensino da disciplina de Artes. Na visão de Andraus"2, ao fazer esse tipo de trabalho, os alunos "podem desenvolver desde tiras e HQs padronizadas (caso queiram), até HQ já montadas em revista (como num fanzine), ou ainda extrapolar a bidimensionalidade indo até a escultura e a instalação, mostrando a variedade criativa de temas e suportes", percebendo e sentindo o produto artístico em sua amplitude.

Dessa forma, o objetivo é proporcionar uma nova experiência cognitiva transformadora e significativa para os jovens, pela produção de um meio de 
comunicação historicamente engajado nas causas sociais e de características notadamente autorais, que, aliadas ao processo histórico e estético dos estudos das artes visuais e da linguagem dos quadrinhos, possam contribuir para a transformação da realidade atual da educação. Pretende-se, desse modo, inserir o jovem em seu papel social de direito, para que ele possa participar, entre outras questões relevantes, das decisões sobre os rumos das políticas públicas em nosso país.

\section{REFERÊNCIAS BIBLIOGRÁFICAS}

ANDRAUS, Gazy. O trabalho com histórias em quadrinhos (HQ) no ensino universitário. In: SANTOS NETO, Elydio; SILVA, Marta Regina Paulo da (orgs.). Histórias em quadrinhos \& Educação: formação e prática docente. São Bernardo do Campo: Universidade Metodista de São Paulo, 2011, pp. 33-55.

; SANTOS NETO, Elydio dos. Dos Zines aos Biografic zines: Narrativas Visuais no Processo de Formação Continuada de Docentes-Pesquisadores. In: Imaginário: Humor, Quadrinhos, Games e Fanzines, n. 1, Paraíba, Marca de Fantasia, 2011, pp. 47-52. Disponível em: <http://marcadefantasia. $\mathrm{com} /$ revistas/imaginario/imaginario-01-10/imaginario-01/imaginario-1 . pdf\#page $=47>$. Acesso em: 20 dez. 2015.

BAtiStOne FILHO, Duílio. Pequena história da arte. 7. ed. Campinas: Papirus, 1996.

CASTELLS, Manuel. A sociedade em rede. 1. v. São Paulo: Paz e Terra, 1999. CAVALCANTE, Luis Adolfo de Oliveira; CEDRO, Wellington Lima. Uma análise lógico-histórica da relação entre as histórias em quadrinhos e a educação. In: PEREIRA, Ana Carolina Costa; ALCÂNTARA, Cláudia Sales de. História em quadrinhos: interdisciplinaridade e educação. São Paulo: Reflexão, 2016, pp. 57-82.

CITELLI, Adilson Odair, Comunicação e Educação: a linguagem em movimento. São Paulo: SENAC, 2004.

. Comunicação, educação e linguagem. In: SOARES, Ismar de Oliveira. Cadernos de educomunicação. Caminhos da educomunicação (coord.). 2. ed. São Paulo: Editora Salesiana, 2003, pp. 63-68.

FERNANDES, Hylio Laganáet al. GIBIOzine — Revista de divulgação científica e cultural. In: Nona Arte - Revista Brasileira de Pesquisas em Histórias em Quadrinhos, v. 1, n. 2, 2013, pp. 35-40. Disponível em: <www2.eca.usp.br/ nonaarte/ojs/index.php/nonaarte/article/view/18>. Acesso em: $18 \mathrm{dez}$. 2015. 
FRANCO, Edgar. História em Quadrinhos e Arquitetura. 2. ed. João Pessoa: Marca de Fantasia, 2012, pp. 8-9. Disponível em <http://marcadefantasia. com/livros/quiosque/hqearquitetura/HQ\%20e\%20 Arquitetura-Edgar\%20 Franco.pdf> Acesso em: 22 out. 2015.

FREIRE, Paulo. Educação como prática da liberdade. 23. ed. Rio de Janeiro: Paz e Terra, 2002.

MAGALHÃES, Henrique. O rebuliço apaixonante dos fanzines. 4. ed. João Pessoa: Marca de Fantasia, 2014.

MAZUR, Dan; DANNER, Alexander. Quadrinhos: história moderna de uma arte global. São Paulo: WMF Martins Fontes, 2014.

PINTO, Renato Donizete. Fanzine na Educação: algumas experiências em sala de aula. João Pessoa: Marca de Fantasia, 2013.

PROENÇA, Graça. História da Arte. São Paulo: Ática, 2003.

RAHDE, Maria Beatriz Furtado. Estética Moderna \& Pós-moderna. Porto Alegre: EDIPUCRS, 2000.

ROSSETTI, Regina; SANTORO JUNIOR, David. Fanzine Punk como mídia alternativa. Revista ALTERJOR, a. 2, v. 2, ed. 4, jul./dez. 2011, p. 67. Disponível em <file:///C:/Users/User/Downloads/153-572-1-PB.pdf>. Acesso em: 10 dez. 2015.

SANTOS, Roberto Elísio dos; VERGUEIRO, Waldomiro. Histórias em quadrinhos no processo de aprendizado: da teoria à prática. In: EccoS Revista Científica, n. 27, São Paulo, Uninove, jan./abr. 2012, pp. 81-95. Disponível em: <http://repositorio.uscs.edu.br/handle/123456789/244>. Acesso em: 14 out. 2015.

SCHAUN, Angela. Educomunicação: reflexões e princípios. Rio de Janeiro: Mauad, 2002.

SOARES, Ismar de Oliveira. Educomunicação: o conceito, o profissional, a aplicação: contribuições para a reforma do ensino médio. São Paulo: Paulinas, 2011. 